\title{
DEVELOPMENT OF AUTOMATED CURING SYSTEM FOR MASS CONCRETE
}

\author{
*Ju-hyung Ha, Youn-su Jung and Yun-gu Cho \\ Hyundai Engineering \& Construction, Research \& Development Division \\ 102-4 Mabuk-dong, Giheung-gu, Yongin-si \\ Gyeonggi-do, 446-716, Korea \\ (*Corresponding author: jhha@hdec.co.kr)
}

\begin{abstract}
New automated curing system for mass concrete has been developed to improve the quality of concrete structure and to save construction time and cost. The principle of this system is the automated water circulation system of heated curing water. Applied curing water on the surface of mass concrete keeps the temperature difference between center and surface of the structure below the threshold of specification. Mock-up test and field application have been conducted to investigate the performance of this system. In the results, new automated curing system reduced the chance of thermal crack occurrence and improved quality of the concrete structure as well.
\end{abstract}

\section{KEYWORDS}

Automated curing system, mass concrete, thermal crack occurrence

\section{INTRODUCTION}

During the hydration of concrete, heat of hydration increases internal temperature of concrete and induce a thermal gap between inside and outside of structure due to low thermal conductivity of concrete. This thermal gap generates tensile stress due to the restraint condition of inside and outside, subsequently thermal cracks occur when the tensile stress reach to the tensile strength of concrete. Therefore heat of hydration should be controlled to prevent thermal cracks of mass concrete by certain cooling methods such as a pre-cooling method or a pipe cooling method.

The pre-cooling method reduces the temperature of mixing materials such as water, aggregate, and cement while the pipe cooling method install a pipe line before concrete placement to pass through cold water during the curing which reduce internal temperature due to heat of hydration. Especially the pipe cooling method is a very effective way to reduce thermal cracks by reducing the heat of hydration of early age concrete since it can reduce internal temperature quickly as low as outside temperature. The pipe cooling method doesn't need any change of mix property and extra tests for quality control while it offers the advantage of reducing heat of hydration. However it needs higher construction cost, more complicate installation works and additional construction time. Therefore a more effective method than current cooling methods is required to reduce thermal cracks.

In this study, researchers developed a new automated curing system which keeps the temperature gap between internal and external of the structure below a temperature criterion to minimize occurrences of the thermal cracks in the mass concrete. The developed curing method is successfully demonstrated through a mock-up test and field application. 


\section{AUTOMATED CURING SYSTEM}

\section{Outline of Automated Curing System}

Automated curing system composed of mainly three parts; a data logger which monitors temperature changes, main and subsidiary water tanks for curing water, and a water heating apparatus and conduits to supply warm curing water to the system (Figure 1). The system measures center temperature and surface temperature of concrete structure using thermal sensors embedded before concrete placement. When the temperature gap between center and surface exceeds the criterion for crack control (generally $20 \square$ ), heated water is supplied automatically on the surface of structure to reduce the temperature gap. This automatic water circulation system minimizes the number of thermal cracks effectively without any structural damage (Figure 2).

The maximum temperature gap between internal and external of an internal restraint mass concrete, $\Delta \mathrm{T}_{\max }$ is defined by CIRIA C660 as equation 1.

$$
\Delta \mathrm{T}_{\max }=\frac{3.7 \varepsilon_{\mathrm{ctu}}}{\alpha_{\mathrm{c}}}
$$

where, $\varepsilon_{\text {ctu }}=$ tensile strain capacity in early age concrete

$\alpha_{c}=$ thermal expansion coefficient of concrete

Based on the equation recommended by CIRIA, $\Delta \mathrm{T}_{\max }$ is $19.9 \square$ when $\alpha_{\mathrm{c}}$ is $1.3 \times 10^{-5}$ and $\varepsilon_{\mathrm{ctu}}$ is $70 \times 10^{-6} \varepsilon$. Moreover British Standard (BS) stipulates the maximum temperature gap between internal and external of concrete structure to control thermal crack as $20 \square$ (when restraint factor, $\mathrm{R}=0.36$, gravel).

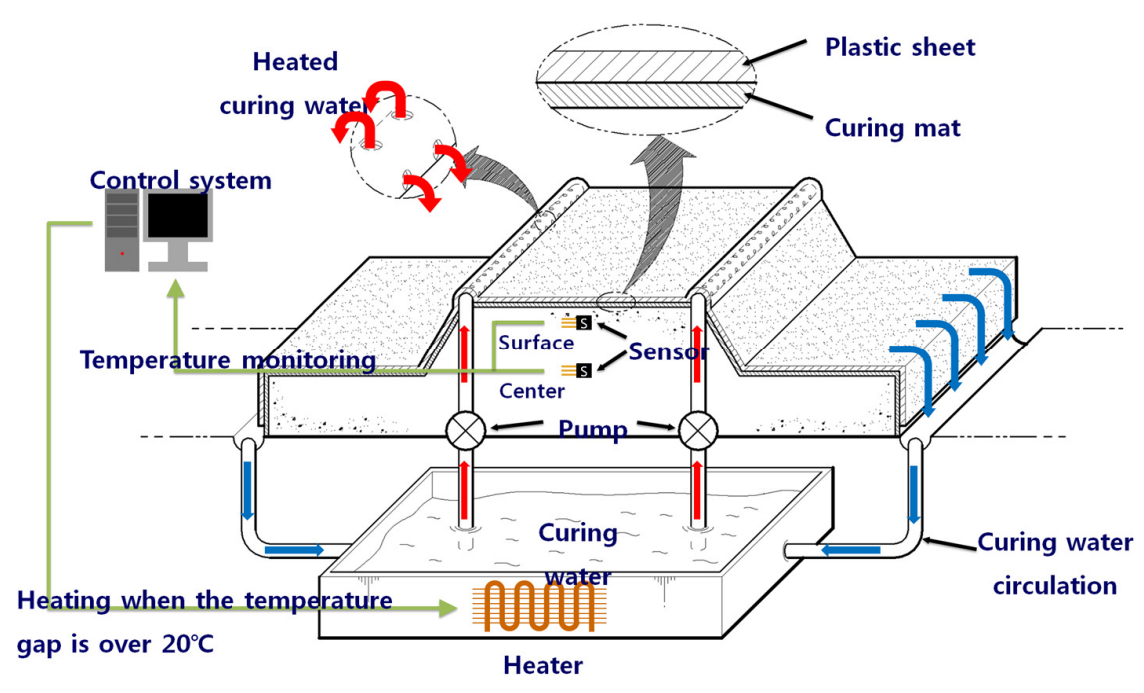

Figure 1 - Conceptual diagram of automated curing system 


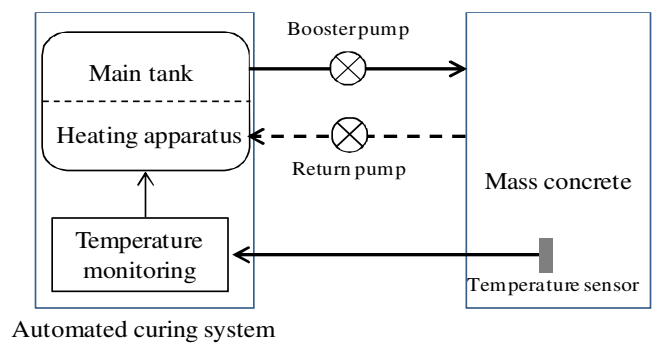

Figure 2 - Outline of system

\section{Characteristics of Automated Curing System}

Automated curing system has not only good performance to control thermal crack but also more benefits as follows:

- It is an economical and environment-friendly system by circulating of curing water for reuse.

- It saves man power by automation as well as raises productivity and quality of mass concrete works by continuous concrete placement.

- It minimizes drying shrinkage cracks due to the continuous wet surface condition of concrete structure while other heating-based curing methods using hot wind cause a lot of cracks.

\section{MOCK-UP TEST}

Two mass concrete specimens are constructed as a mock-up test to evaluate the effectiveness of controlling thermal cracks using the automated curing system in a field condition. Test results are summarized regarding material properties, construction procedure, installing sensors, and test methods.

\section{Test Materials and Concrete Mix Property}

Portland blast-furnace slag cement was mixed with river sand and crushed stone. Water cement ratio was $38.5 \%$ and target slump was $15 \mathrm{~cm}$. More detail information is explained in Table 1 and Table 2.

Table 1 - Physical properties

\begin{tabular}{c|l}
\hline Material & \multicolumn{1}{c}{ Physical properties } \\
\hline \hline \multirow{2}{*}{ Cement } & $\begin{array}{l}\text { Blast-furnace slag cement } \\
\left.\text { (Density: } 2.92 \mathrm{~g} / \mathrm{cm}^{3}, \text { Specific surface area: } 4720 \mathrm{~cm}^{2} / \mathrm{g}\right)\end{array}$ \\
\hline $\begin{array}{c}\text { Fine } \\
\text { aggregate }\end{array}$ & $\begin{array}{l}\text { River sand } \\
\left(\text { Density: } 2.57 \mathrm{~g} / \mathrm{cm}^{3}, \text { absorption: } 1.48 \%\right)\end{array}$ \\
\hline $\begin{array}{c}\text { Coarse } \\
\text { aggregate }\end{array}$ & $\begin{array}{l}\text { Crushed aggregate } \\
\left(\text { Size: } 20 \mathrm{~mm}, \text { Density: } 2.69 \mathrm{~g} / \mathrm{cm}^{3}, \text { absorption: } 0.56 \%\right)\end{array}$ \\
\hline
\end{tabular}


Table 2 - Mix proportion

\begin{tabular}{|c|c|c|c|c|c|c|}
\hline \multirow{2}{*}{$\begin{array}{l}\mathrm{W} / \mathrm{C} \\
(\%)\end{array}$} & \multirow{2}{*}{$\begin{array}{l}\text { S/a } \\
(\%)\end{array}$} & \multirow{2}{*}{$\begin{array}{l}\text { Slump } \\
(\mathrm{cm})\end{array}$} & \multicolumn{4}{|c|}{ Unit weight $\left(\mathrm{kg} / \mathrm{m}^{3}\right)$} \\
\hline & & & Water & Cement & Sand & Gravel \\
\hline 38.5 & 46.3 & 15 & 165 & 429 & 634 & 945 \\
\hline
\end{tabular}

\section{Construction of Test Specimen}

Test specimens were constructed as a mass concrete without reinforcing steel bar (width: $3 \mathrm{~m}$, height: $2 \mathrm{~m}$, length: $5 \mathrm{~m}$ ). Two specimens are constructed at the same time as shown Photo 1 . One is cured by automated curing system which developed in this study (Mass-1) while automated curing is not applied in the other. Water way is installed beside of specimens to recycle curing water and a pump is used to retrieve water (Photo 2). Photo 3 shows specimens during the curing and photo 4 shows completed test specimens after curing.

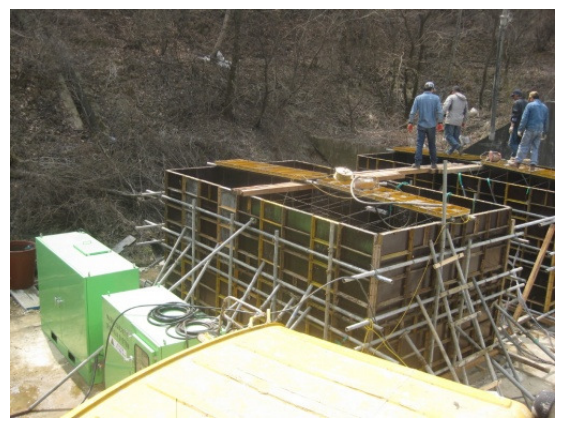

Photo 1 - Concrete pouring

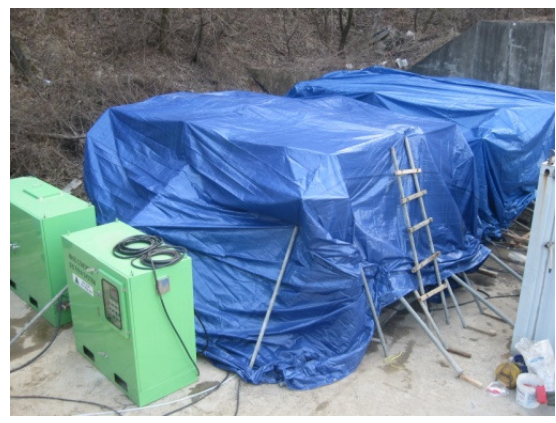

Photo 3 - Concrete curing

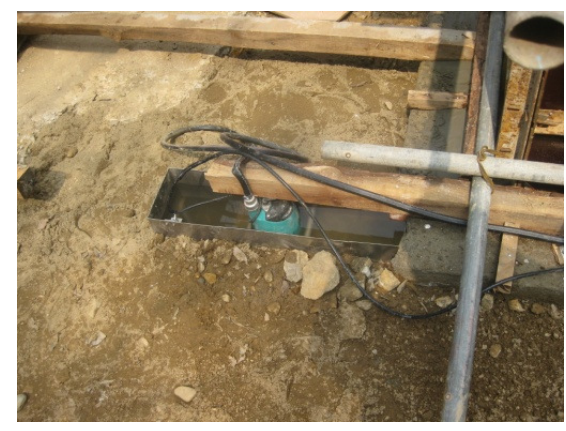

Photo 2 - Waterway

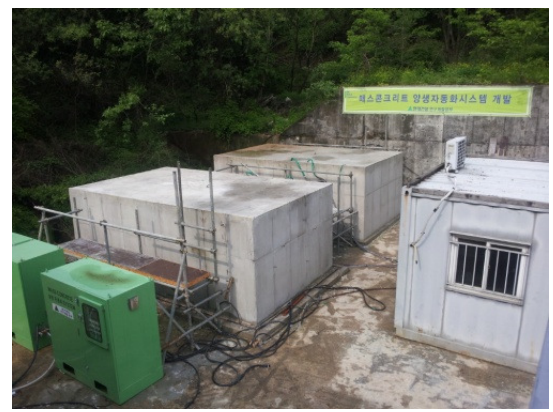

Photo 4 - Completed specimens

\section{Installation of Sensors}

The locations of installing sensors are decided based on the analysis of temperature and stress. Temperature change of specimen is monitored using the temperature sensors installed in the center and surface of specimen (Thermocouple T-type: minimum -60, maximum $100 \square$ ). The automated curing system supplies appropriate heated curing water to the surface of specimen 
automatically when the temperature gap between center and surface of specimen exceeds $20 \square$ to keep the temperature difference smaller than $20 \square$. The sensors for stress are installed on the surface and center of test specimens to monitor thermal stress change. The stress sensors (GK-N202, measurement range: $20 \mathrm{MPa}$ ) measure stress of concrete directly since it has load cell to itself.

\section{Test Procedure}

Mass- 1 test specimen is cured by the automated curing system while Mass-2 test specimen is cured by general field curing method with curing mat as shown in Figure 4. Temperature and stress were measured from the start of concrete placement; every 15 minute measuring during first 3 days, after then every 1 hour check. Automated curing system started after 17 hours of concrete work until 7 days. Number, length, and width of cracks are measured using crack scale and crack micro scope at the end of curing. Conceptual diagram of mock-up test is shown in Figure 4.

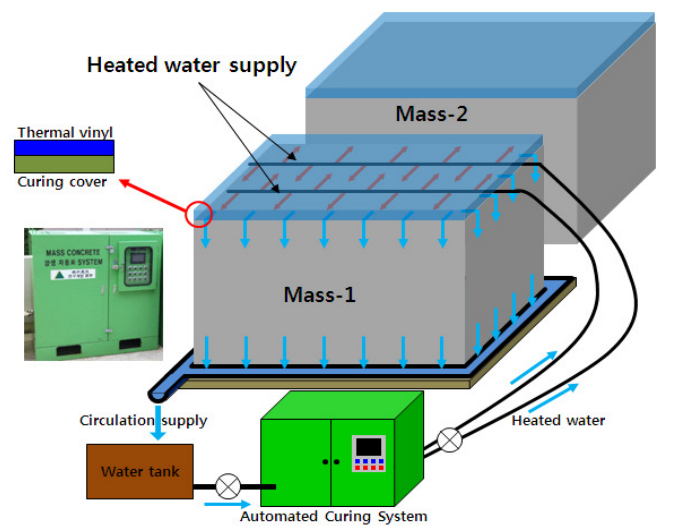

Figure 3 - Conceptual diagram of mock-up test

\section{TEST RESULTS AND ANALYSIS}

\section{Temperature Change}

The temperature change of mass concrete test specimen is shown in Figure 4. The initial temperature of concrete was $25.4 \square$ and the temperature of Mass- 1 test specimen cured by the automated curing system reached to the maximum temperature of $61.3{ }^{\circ} \mathrm{C}$ after 38 hours while the temperature of Mass-2 test specimen cured by general field curing method reached to the maximum temperature of $58.5 \square$ after 35 hours. After the peak temperature, the internal temperature of Mass-1 test specimen diminished to $40 \square$ at 75 hours later from the peak while the internal temperature of Mass-2 test specimen diminished to $28 \square$ at 75 hours later from the peak. Mass-2 test specimen experienced faster temperature drop than Mass-1 test specimen cured by the automated curing system.

Figure 5 shows temperature differences between center and surface of test specimens which calculated from the temperature measurements of $\mathrm{T} 1$ and $\mathrm{T} 2$ in Figure 4. The temperature difference of Mass-1 test specimen satisfied the thermal cracking criteria, $20 \square$; however, the 
temperature difference of Mass-2 test specimen was maximum $29 \square$ and could not satisfied the thermal cracking criteria, $20 \square$ as shown in Figure 5 .

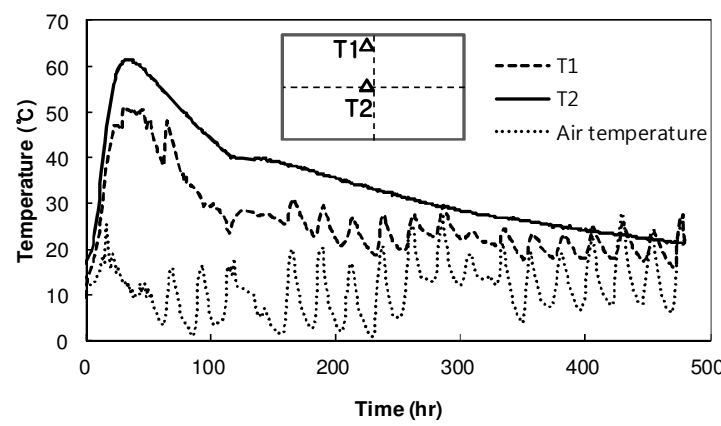

(a) Mass-1 specimen

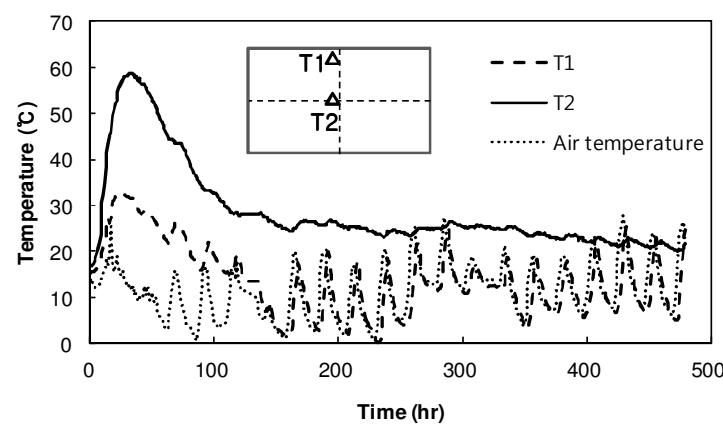

(b) Mass-2 specimen

Figure 4 - Temperature change

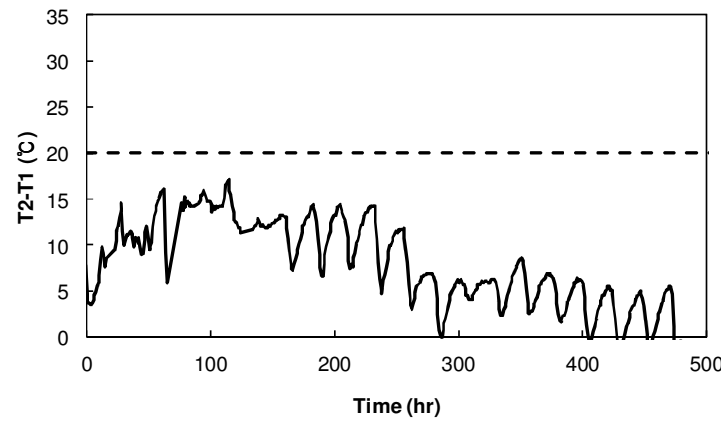

(a) Mass-1 specimen

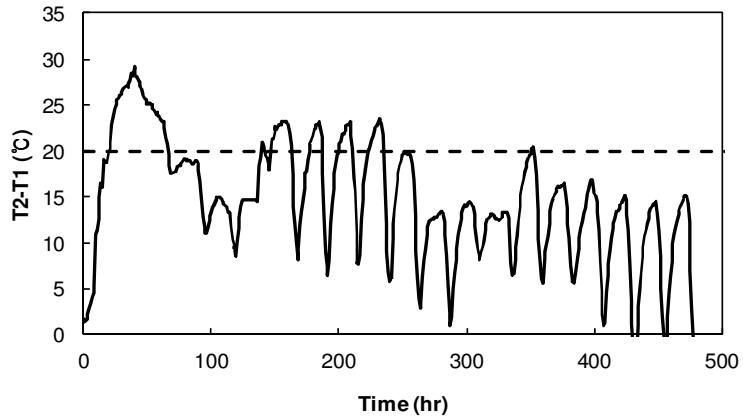

(b) Mass-2 specimen

Figure 5 - Internal-external temperature difference

\section{Crack Analysis}

Table 3 shows the details of crack occurring. Five cracks are generated on the perpendicular direction of principal stress and three cracks are generated on the parallel direction of principal stress. There was no crack occurring on Mass-1 test specimen cured by the automated curing system; however, Mass-2 test specimen shows 8 cracks as detailed in Table 3. Especially a wide crack over $0.4 \mathrm{~mm}$ was monitored from Mass- 2 test specimen, which can cause harmful effect to the durability of specimen. 
Table 3 - Cracks in Mass-2 specimen

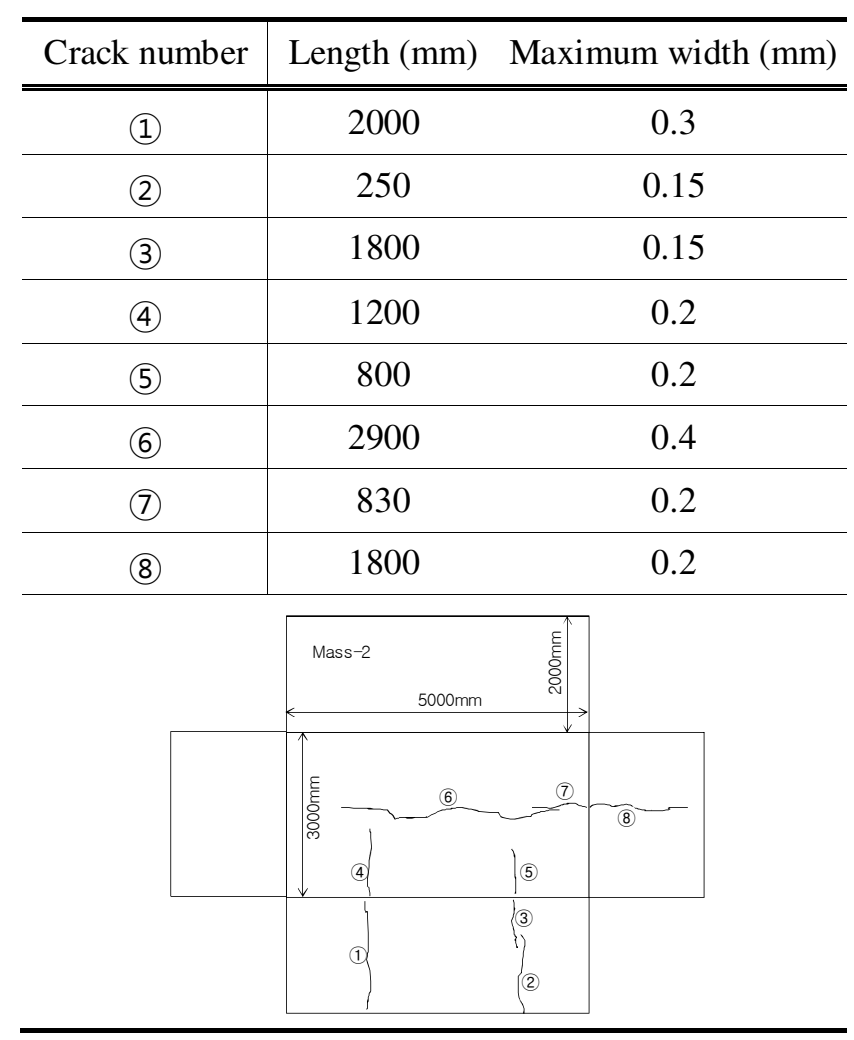

FIELD APPLICATION

After verifying the effectiveness of the automated curing system for controlling effect of thermal cracking in case of mass concrete through mock-up test, it was applied to a real construction site curing of the concrete foundation for thermal power station turbine. Field application details are summarized as follows:

- Site: thermal power station

- Date: Jun 29, 2012 July 10, 2012

- Application part: concrete foundation of turbine

- Size: $54.7 \mathrm{~m} \times 15.5 \mathrm{~m} \times 2.6 \mathrm{~m}$

- Volume: $2,500 \mathrm{~m}^{3}$

\section{Field Application Results}

Thermal difference between the center and surface of concrete was set as lower than $20 \square$ to control thermal cracking occurrence during the field application. The temperatures of center and surface of concrete and air temperature were measured using thermal sensors. Thermal difference between the center and surface of concrete was successfully controlled as 
under $20 \square$ by the automated curing system except the system discontinuous period due to a stoppage of power supply. Six cracks narrower than $0.1 \mathrm{~mm}$ are detected during the crack inspection after curing period; however, that crack number is very small considering huge size of the structure and insignificant for structural integrity.

\section{CONCLUSION}

A mock-up test and field application were conducted to evaluate the performance of automated curing system to control the thermal cracks of mass concrete. Test results showed that the automated curing system could be used as a effective way to control thermal cracking since it is able to control the temperature difference between center and surface of concrete and improve the quality of concrete. Therefore, it will become very helpful method to reduce thermal cracking of massive and important concrete structures.

\section{REFERENCES}

Korea Concrete Institute (2010). Thermal Crack Control of Mass Concrete. Concrete Practices Manual.

Back DI, Kim MS. (2008). Application of Heat Pipe for Hydration Heat Control of Mass Concrete. Journal of the Korea Concrete Institute , 20(2), pp.157-164.

P.B. Bamforth. (2007). Early-age Thermal Crack Control in Concrete. CIRIA C660, London.

Structural use of concrete-Part1 (1997). Code of practice for design and construction. BS 8110-1. British Standards Institution, London.

American Society for Testing and Materials, ASTM (2012). Standard Specification for Blended Hydraulic Cements. ASTM C595., Philadelphia.

Journal of the Japan Society of Civil Engineers, JSCE (1996). Specification for Design and Construction of Concrete Structures (Construction part) - Mass Concrete., pp. 173-193.

ISO 1920-3 (2004). Testing of concrete -- Part 3: Making and curing test specimens. International Organization for Standardization.

ISO 1920-4 (2005). Testing of concrete -- Part 4: Strength of hardened concrete. International Organization for Standardization. 